\title{
A new method for ash melthod thermo-analysis based on mineral quantity
}

\author{
ZHAO YongChun $^{1,2^{*}}$, ZHANG JunYing $^{1^{*}}$, SHAO XinYu ${ }^{2} \&$ ZHENG ChuGuang $^{1}$ \\ ${ }^{1}$ State Key Laboratory of Coal Combustion, Huazhong University of Science \& Technology, Wuhan 430074, China; \\ ${ }^{2}$ School of Mechanical Science \& Engineering, Huazhong University of Science \& Technology, Wuhan 430074, China
}

Received November 18, 2009; accepted January 7, 2010

\begin{abstract}
Ash deposition has a major impact on safe and economic operation of coal-fired boiler. A new method for ash melting thermo-analysis based on X-ray diffraction mineral quantitative analysis was developed; the classical thermal analysis theory was used to describe the dynamic behavior of ash melting. The low-temperature ash melting process curve was acquired. Compared with the conventional method of ash fusibility, the new method of ash melting characteristic curve reflects the ash melting dynamic better. The ash melting characteristic curve reveals the multi-stage reaction process of minerals melting, explains the gradual increase of mineral melting process in theory.
\end{abstract}

mineral quantitative thermo-analysis, melting, ash deposit

Citation: Zhao Y C, Zhang J Y, Shao X Y, et al. A new method for ash melthod thermo-analysis based on mineral quantity. Chinese Sci Bull, 2011, 56: 1043-1047, doi: 10.1007/s11434-011-4463-6

The melting behavior of ash particles and viscosity of deposit are two decisive factors of slagging [1]. Recently, many studied reported the ash deposition, a variety of methods have been widely used to speculate ash melting behavior [1-6]. The most commonly used is the ash fusion temperature method based on the image recognition. However, the reproducibility of this method is poor and the sample preparation process of this method is complicated. In addition, even more noteworthy is that only four instantaneous characteristic temperatures can be given by this method, and the transformation process of minerals and real-time behavior of ash particles in the actual boiler can not be predicted $[2,3]$. Another defect of this method is that the ash fusion temperatures are just reflecting the melting behavior of ash particles, which is essentially different from the melting behavior of minerals in a boiler. Some studies have shown that the melting temperature of deposit in a boiler is less than that of ash prepared in a lab-scale reactor [5]. Therefore the study on the melting characteristics of

*Corresponding authors (email: yczhao@ hust.edu.cn; jyzhang@hust.edu.cn) minerals in coal must integrate their migration and transformation behaviors during coal combustion.

In addition, a multi phases diagram has been used to analyze the melting of coal ash broadly $[2,7,8]$. Phase diagram can explain the co-fusion of multi-components very well. However, this method is based on the chemical composition of elements, not taking into account the mineral structure in ash. While for ashes which have the same chemical composition, the varied crystal structure may lead to significant difference in the melting characteristics of ash.

According to the current research status and existing problems, this paper proposes a new method for ash melting thermo-analysis based on mineral quantitative analysis (MQTA). The Rietveld mineral quantitative analysis method and simultaneous thermal analysis (STA) method are combined. The temperature change thermal curve, mineral structure evolution and weight loss data are obtained simultaneously. The STA thermal curve is transformed to ash melting curve in real-time, which has great significance on the study of dynamic process of mineral partition and melting. 


\section{Theoretical basis of mineral melting thermo- analysis}

The reaction rate of gas solid chemical reaction can be acquired easily to apply thermal gravimetric analysis. Compared with ordinary gas solid reaction, melting process has significant difference. Melting reaction is a complex physical-chemical process that the reactant mass changed little. The slight mass change is not enough to characterize the reaction progress accurately. Therefore, a simple TGA experimental method cannot be used for melting mechanism studies. The thermal analysis is more suitable for the investigation of reaction dynamic.

The progress of melting reaction is proportional to the endotherm during the process, thus the reaction progress can be reflected by DSC curve. The reaction kinetic can be established based on DSC signal which reflects melting energy in theory. As shown in Figure 1, $S$ is the area between DSC curve and baseline of the whole reaction process, $S$ is the area of a certain time during the reaction process. The DSC signals represent heat flow $\mathrm{d} H / \mathrm{d} \tau$, then $S$ can be used to represents the reaction heat. The reaction fraction of a certain time can be expressed as follows:

$$
a=\frac{H}{H_{0}}=\frac{S^{\prime}}{S},
$$

where $\alpha$ is reactant conversion rate, $H$ is heat of the reaction for the moment, $H_{0}$ is total heat of the reaction.

At this point the concentration of reactant can be calculated as follows:

$$
1-a=\frac{H_{0}-H}{H_{0}}=\frac{S-S^{\prime}}{S}=\frac{S^{\prime \prime}}{S} .
$$

The STA method based on TGA-DSC has been used to characterize the melting reaction of a single component successfully [4,5]. In order to know the reaction heat, the temperature which obtained simultaneously with TGA can be used to compare with inert reference. The melting reaction

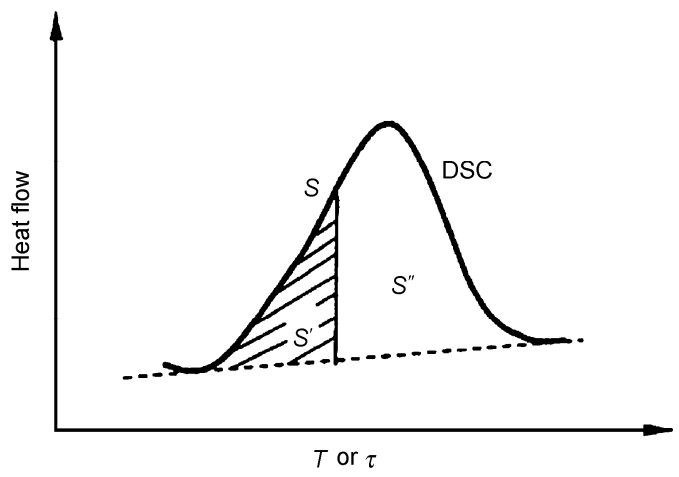

Figure 1 Melting reaction DSC curve. is an endothermic process without weight change. The DSC signal of pure compound melting showed a single endothermic peak. So if we know the melting enthalpy, the DSC curve can be transformed into melting curve easily. However, for the ash with complex composition, different components melt at different temperatures that will result in the overlap of endothermic peaks. In addition, the formation process of ash not only contained ash melting but also accompanied the evaporation of some components. Thus in order to obtain the melting curve from STA curve, the heat related to other processes than melting must be subtracted from the raw DSC signal first.

Mineral evaporation is the source of ash deposits in coal-fired boiler. The initial deposit derived from the condensation of inorganic vapors made melted particles adhere on the heat transfer surface easier $[6,9,10]$. Thus, a precise quantitative description of the mineral evaporation is of great significance to reveal the mechanism of ash deposition and to mitigate slagging on the heat transfer surfaces of the boiler. The STA method used by Hansen et al. was just to characterize the melting of ash which belongs to the second reaction [4]. It does not accurately reflect the melting of minerals during coal combustion. The proposed MQTA method in this paper is to first use low-temperature plasma ashing method to separate the inorganic minerals from coal, and then conduct the STA analysis of low temperature ash (LTA) to get the TGA-DTA-DSC curves. At last, Rietvild mineral quantitative method is combined to subtract the energies of mineral transformation and evaporation processes.

\section{Mineral thermo-analysis curves}

Three typical coals (XLT, SF, YZH) were selected to carry out MQTA analysis, and the melting characteristics of coals with different mineral composition were discussed. Thermo gravimetric analysis was conducted on STA 409 thermal analyzer made by German NETZSCH company. The computer-controlled system for temperature-programmed was used in this analyzer, and the weight loss with temperature change was recorded by microbalance system. Experiment temperature range is between $30^{\circ} \mathrm{C}$ and $1450^{\circ} \mathrm{C}$, the heating rate is $50^{\circ} \mathrm{C} / \mathrm{min}$, the flow rate of air is $100 \mathrm{~mL} / \mathrm{min}$. Each sample is about $5 \mathrm{mg}$.

The typical STA curves of XLT-LTA are shown in Figure 2. There are five obvious weight loss peaks in the DTG curve, locating at $120^{\circ} \mathrm{C}, 380^{\circ} \mathrm{C}, 590^{\circ} \mathrm{C}, 740^{\circ} \mathrm{C}$, and $1200^{\circ} \mathrm{C}$, respectively. Combining the mineral quantitative result (Table 1), it is easy to find that the weight loss peak at $120^{\circ} \mathrm{C}$ and $380^{\circ} \mathrm{C}$ belong to the dehydration of adsorbed water and hydrated gypsum mineral. The peak at about $590^{\circ} \mathrm{C}$ represents the decomposition of kaolinite and illite, $740^{\circ} \mathrm{C}$ peak originates from the weight loss of calcite decomposition. 
Table 1 Mineral composition and content in XLT-LTA (wt\%)

\begin{tabular}{cc||cc}
\hline Coal sample & XLT & Coal sample & XLT \\
\hline LTA & 18.7 & Calcite & 13.8 \\
Kaolinite & 8.5 & Bassanite & 23.6 \\
Illite & 21.3 & Pyrite & 5.5 \\
Quartz & 22.9 & Anatase & 4.4 \\
\hline
\end{tabular}

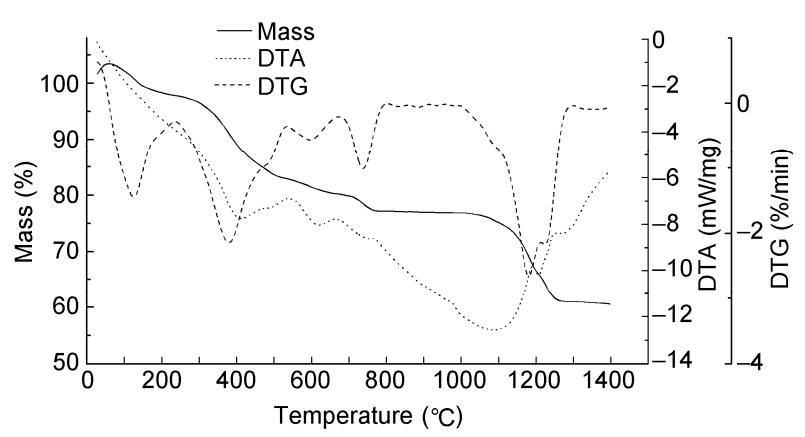

Figure 2 TG-DTA-DTG curves of XLT-LTA in air.

The peak at about $1200^{\circ} \mathrm{C}$ is the overlap of two weight loss peaks.

The mineral composition of XLT-LTA (Table 1) indicated that there is no decomposition weight loss reaction after the temperature rising to $1000^{\circ} \mathrm{C}$. Whereas, two endothermic peaks were found from the DSC curve around $1200^{\circ} \mathrm{C}$. This result implies that the weight loss peaks at about $1200^{\circ} \mathrm{C}$ were mainly due to the mineral evaporation. The further detailed analysis shows that, there is a weak endothermic peak without weight loss from point $\mathrm{A}\left(809^{\circ} \mathrm{C}\right)$ to point $\mathrm{B}\left(1013^{\circ} \mathrm{C}\right)$ in the DSC curve (Figure 3$)$. This is a typical melting process. As the temperature increased further, sample weight begins to decrease rapidly until the point $\mathrm{C}\left(1277^{\circ} \mathrm{C}\right)$, after that the weight of sample keeps constant. There are obvious endothermic peaks between BC and $\mathrm{CD}$ in DSC curve, the $\mathrm{BC}$ section with an obvious weight loss has mineral composition evaporation, whereas the $\mathrm{CD}$ section without mass change belongs to another melting process.

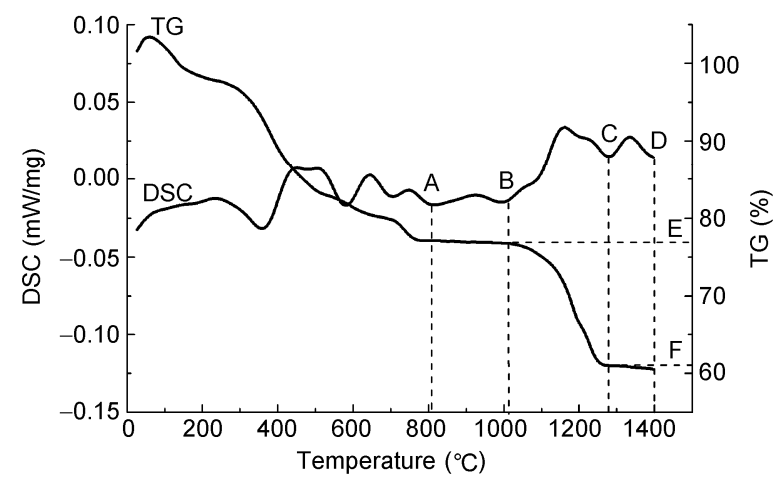

Figure 3 TG-DSC curves of XLT-LTA-air.
The integral calculation of total heat was conducted, starting from point $\mathrm{A}$ to point $\mathrm{D}$, the area under the blank baseline was subtracted to get the total thermal change of mineral melting and evaporation (Figure 4). The evaporation process is usually accompanied by mineral melting, so the thermal effect of segment BC is not entirely mineral evaporation, but rather a combination of mineral melting and evaporation. To accurately quantify the mineral melting process, the mixed thermal effects of segment $\mathrm{BC}$ should be distinguished. However, due to the complex mineral composition in LTA, the direct calculation of thermal effect of melting process is very difficult. Each component melts at different temperatures, and sometimes different components may be co-fusion. In comparison, the evaporation enthalpy of mineral composition is relatively easy to calculate. The evaporation process is mainly focused on the $1013^{\circ} \mathrm{C}$ to $1277^{\circ} \mathrm{C}$ for this coal, and the total weight loss of evaporation can be acquired easily from TG curve (segment EF). So here we use an approximate method to estimate the enthalpy of vaporization, and then use the total heat minus the heat of evaporation to get the melting endotherm, thus the relationship between melting heat change and temperature can be constructed.

The mineral composition of XLT-LTA includes kaolinite, illite, quartz calcite, and bassanite. The contents of minerals are listed in Table 1. The vaporization enthalpy of each component can be obtained from thermodynamic database. So the concept of average evaporation enthalpy of LTA $H_{\text {LTA }}$ is defined as follows:

$$
H_{\mathrm{LTA}}=\sum_{1}^{n} H_{i} C_{i}
$$

where $H_{i}$ is the evaporation enthalpy of component $i, C_{i}$ is the content of component $i$.

The average evaporation enthalpy of XLT-LTA was calculated, as about $10.57 \mathrm{~kJ} / \mathrm{g}$. Assume that the average evaporation enthalpy is not changed after component melting, so the evaporation enthalpy during $\mathrm{BC}$ section can be calculated by the total weight loss. The mass change can be

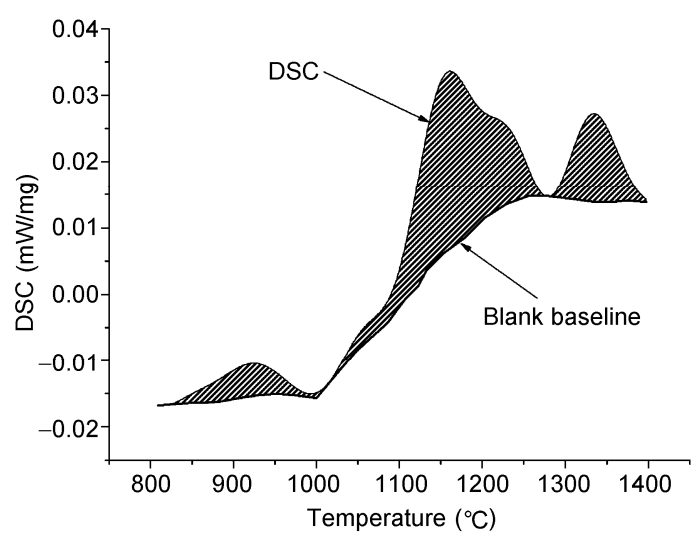

Figure 4 Mineral melt heat curve. 
read from TG curve is about $15.7 \%$ (segment EF), the total mass of ash sample is known, so the evaporation enthalpy of BC segment can be calculated, is about $8.29745 \mathrm{~J}$. Assuming the evaporation is proportional to temperature, and then the mixed thermal effect in Figure 4 can be separated, the single melting heat curve can be calculated (Figure 5). The shape of melting curves with and without subtract evaporation enthalpy are similar. The mineral melting of XLT coal is a typical multi-stage process, these two melting curves reflected the melting process accurately. However, the melting rate at high temperature is faster than that at low temperature, so the melting curve subtracted the evaporation enthalpy is more reasonable.

Compared with the ash fusion temperatures that determined by national standard GB/T219-1996 (Figure 6), the temperature of mineral began to melt is $300^{\circ} \mathrm{C}$, lower than the initial deformation temperature (IDT), which is consistent with the results of Hansen [4, 5]. Huggins and Huffman also found that the temperature of ash began to melt is $200-400^{\circ} \mathrm{C}$, lower than IDT [5]. The ash melting temperature in STA experiment measured by Hansen is about $150^{\circ} \mathrm{C}$ lower than IDT. For XLT-LTA, when the temperature reached at IDT, the XLT-LTA already has $12 \%$ of the

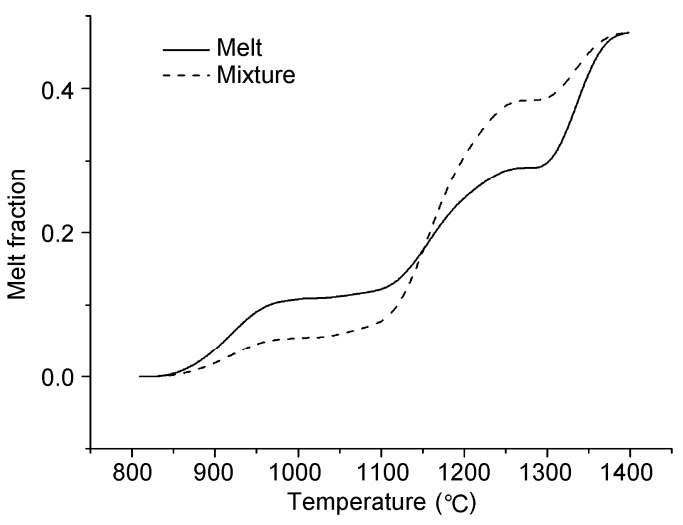

Figure 5 Melting curve of minerals.

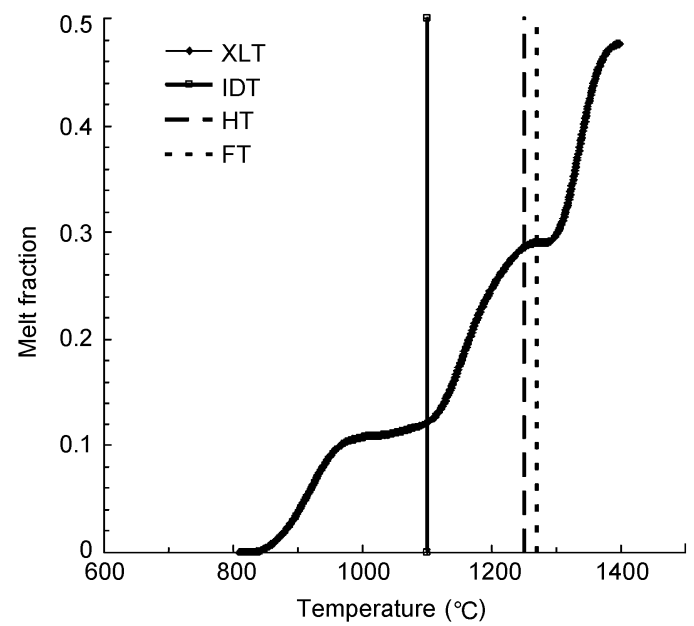

Figure 6 Comparison of melting curve and ash fusion temperatures of XLT. mineral melted (Figure 6). In Hansen's experiments, the biomass ash already has $51 \%$ components melted, coal ash has up to $36 \%$ components melted [4]. However, the mineral melt has not increased significantly with the temperature rising from hemispherical temperature (HT) to flux temperature (FT).

The ash fusion temperature is related to its chemical composition and the ratio of acidic oxides and alkaline oxides. Normally, ash is difficult to melt with the increase of acidic oxides like $\mathrm{Al}_{2} \mathrm{O}_{3}$ content. Whereas, the alkaline oxides like $\mathrm{Fe}_{2} \mathrm{O}_{3}, \mathrm{CaO}, \mathrm{K}_{2} \mathrm{O}$, etc. can promote the ash fusion. However, due to the complexity of coal composition, the same chemical composition of coal sample, in the mineral composition can vary widely. Most of the previous studies focused on differences in chemical composition of ash, but ignored the impact of original mineral composition of coal. Based on the above-mentioned MQTA method, three typical easy-slagging coal samples (XLT, SF, YZH) were selected to conduct the experimental analysis. The melting curves of these three LTAs are shown in Figure 7. The initial melting temperature of XLT-LTA is the lowest, and the melting percent at $1400^{\circ} \mathrm{C}$ is also the lowest, only $47.7 \%$. The YZH-LTA has the largest melting percent, up to $79.9 \%$ at $1400^{\circ} \mathrm{C}$. Although both of them have similar chemical compositions, the melting characteristics are different. This also validates that the mineral composition has significant influence on ash fusion. Similar to XLT-LTA, the melting processes of SF-LTA and YZH-LTA have obvious multiple stages. The initial stage is slow, and then the reaction rate increase sharply. This is mainly because of the various mineral compositions of LTA samples. The mixture eutectic happened during the melting process which accelerated the fusion of minerals [1].

\section{Conclusions}

The ash melting behavior plays an important role in the

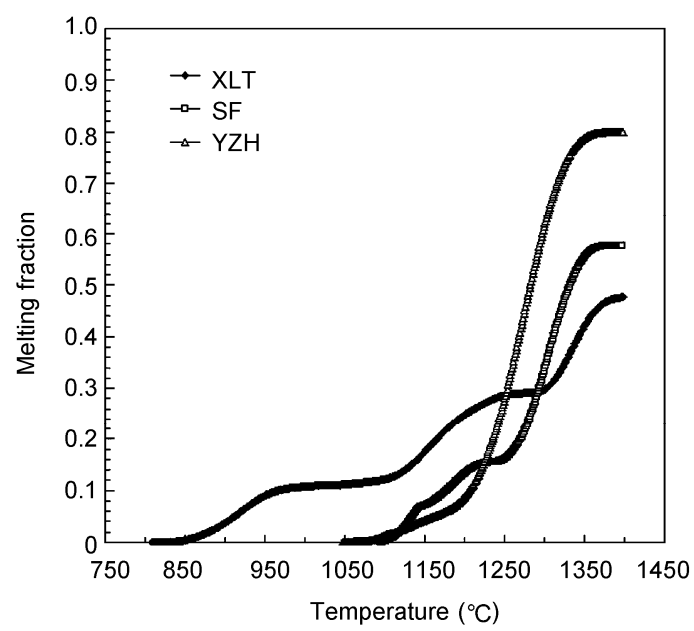

Figure 7 Melting curves of different coal samples. 
evaluation of coal slagging. In this paper, a new method based on mineral quantitative analysis and melting thermoanalysis (MQTA) was established to characterize the melting process. The ash melting curves were calculated. Compared with the normal ash fusion temperature, the ash melting curve can reflect the variation of ash fusion process better. The melting of minerals in coal is a multi-stage reaction process. As the reaction took place, the melt reaction rate gradually increased, and then the reaction rate tended to moderate. The melting curve that provides the dynamic melting process has great significance on the slagging prediction of coal-fired utility boiler.

This work was supported by the National Natural Science Foundation of China (50906031, 40972102, 50936001, 50721005), National Basic Research Program of China (2010CB227003), and Innovation Foundation Program of Huazhong University of Science and Technology (2009012).

1 Vorres K S. Mineral Matter and Ash in Coal. Washington DC:
American Chemical Society, 1986

2 Bryers R W. Fireside slagging, fouling, and high-temperature corrosion of heat-transfer surface due to impurities in steam-raising fuels. Prog Energy Combust Sci, 1996, 22: 29-120

3 Zbogar A, Frandsen F J, Jensen P A, et al. Heat transfer in ash deposits: A modelling tool-box. Prog Energy Combust Sci, 2005, 31: 371-421

4 Hansen L A, Frandsen F J, Dam-Johansen K, et al. Quantification of fusion in ashes from solid fuel combustion. Thermochim Acta, 1999, 326: $105-117$

5 Hansen L A, Frandsen F J, Dam-Johansen K, et al. Characterization of ashes and deposits from high-temperature coal-straw co-firing. Energy Fuels, 1999, 13: 803-816

6 Zbogar A, Frandsen F, Jensen P A, et al. Shedding of ash deposits. Prog Energy Combust Sci, 2009, 35: 31-56

7 Kondratiev A, Jak E. Predicting coal ash slag flow characteristics (viscosity model for the $\mathrm{Al}_{2} \mathrm{O}_{3}-\mathrm{CaO}-\mathrm{FeO}^{\prime}-\mathrm{SiO}_{2}$ system). Fuel, 2001, 80: 1989-2000

8 Fukuda K, Iwata T, Yoshida $\mathrm{H}$. Melt differentiation and crystallization of clinker minerals in a $\mathrm{CaO}-\mathrm{SiO}_{2}-\mathrm{Al}_{2} \mathrm{O}_{3}-\mathrm{Fe}_{2} \mathrm{O}_{3}$ pseudoquaternary system. Cem Concr Res, 2010, 40: 167-170

9 Gupta S, Gupta R, Bryant G, et al. Characterization of ash deposition and heat transfer behavior of coals during combustion in a pilot-scale facility and full-scale utility. Energy Fuels, 2009, 23: 2570-2575

10 Wall T F. Mineral matter transformations and ash deposition in pulverised coal combustion. Symp (Int) Combust, 1992, 24: 1119-1126

Open Access This article is distributed under the terms of the Creative Commons Attribution License which permits any use, distribution, and reproduction in any medium, provided the original author(s) and source are credited. 